\title{
Valence Stabilization of Fe(II) Ions during Extended Gamma Irradiation of Their Aqueous Acidic Solutions Containing Phenol, Acetone, 4-Ethylpyridine or Hydrazine Hydrate
}

\author{
M. F. Barakat ${ }^{*}$, M. M. Abdel Hamid ${ }^{2}$ \\ ${ }^{1}$ Nuclear and Radiological Control Authority, Cairo, Egypt \\ ${ }^{2}$ Hot Labs Center, Atomic Energy Authority, Cairo, Egypt \\ Email: ${ }^{*}$ mbarakat49@yahoo.com
}

Received 11 February 2015; accepted 9 April 2015; published 10 April 2015

Copyright (C) 2015 by authors and Scientific Research Publishing Inc.

This work is licensed under the Creative Commons Attribution International License (CC BY).

http://creativecommons.org/licenses/by/4.0/

(c) (i) Open Access

\begin{abstract}
Valence stabilization of polyvalent ions in acidic solutions during gamma irradiation is an important issue in nuclear aqueous chemical technology. Radiolysis and self irradiation problems encountered during chemical reprocessing of nuclear fuel or during chemical separation of transuranium elements or fission products are extremely important. Consequently studies on valence stabilization of polyvalent ions in strong gamma irradiation fields are very useful. In our previous publications, the valence stabilization of Fe(II) ions in acidic solutions during continuous gamma irradiation was achieved by using an inorganic compound; such as sodium sulfite, or some organic additives such as aliphatic alcohols, aldehyds or acids prior to irradiation. It was found that the efficiency of valence stabilization depends on the amount and chemical structure of the added compounds. In the present work, valence stabilization of divalent iron during gamma irradiation was studied in presence of some organic additives, belonging to some other classes of organic compounds such as Phenol (aromatic alcohol), Acetone (aliphatic ketone), 4-Aminopyridine (heterocyclic amino compound) and Hydrazine hydrate (aliphatic amino compound) to complement our previous studies. The results showed that valence stabilization of Fe(II) in presence of these compounds depends also on the amount and chemical structure of the additive used. Some interaction mechanisms have been proposed.
\end{abstract}

${ }^{*}$ Corresponding author.

How to cite this paper: Barakat, M.F. and Abdel Hamid, M.M. (2015) Valence Stabilization of Fe(II) lons during Extended Gamma Irradiation of Their Aqueous Acidic Solutions Containing Phenol, Acetone, 4-Ethylpyridine or Hydrazine Hydrate. World Journal of Nuclear Science and Technology, 5, 88-101. http://dx.doi.org/10.4236/wjnst.2015.52008 


\section{Keywords}

\section{Water Radiolysis, Valence Stabilization, Extended Gamma Irradiation, Competitive Reactions, Polyvalent Ions, Protective Effects}

\section{Introduction}

Valence change of polyvalent ions in aqueous acidic solutions in strong gamma irradiation fields can seriously affect the mechanism of some chemical processes. That valence change occurs as a result of the effect of the primary products formed by water radiolysis [1]-[3]. In modern radiochemical practice, valance stabilization of gamma irradiated polyvalent metal ions is an important issue [4]. Moreover, valence stabilization of polyvalent ions can reduce the negative effects of some chemical processes. For example, crud formation $\left(\mathrm{Fe}_{3} \mathrm{O}_{4}\right)$ on stainless steel or carbon steel used in boiling water reactors [5] could be suppressed if the valence of the released $\mathrm{Fe}(\mathrm{II})$ is protected against oxidation to the trivalent state that leads to crud formation.

In previous publications, the valence of Fe(II) ions was stabilized, when subjected to continuous gamma irradiation, in presence of either sodium sulfite as a reducing agent [6] or some organic compounds e.g., organic acids, aldehyds or alcohols [7]. It has been reported that protective effects occur as a result of the competitive reactions taking place between the chemical additive and the polyvalent metal ions for the oxidizing or reducing species formed by water radiolysis. The existence of organic additives in Fe(II) acidic solutions, enhances valence stability of the divalent iron ions against oxidation during continuous gamma irradiation. That behavior depends on the type and concentration of the organic additive used. In order to further understand the prevailing mechanisms, Fe(III) ions were used instead of Fe(II) in the irradiated solutions and it was found that Fe(III) ions were first reduced to the divalent state and the formed Fe(II) ions remained protected against oxidation, depending also on the type and concentration of the organic additive used [7].

In the present work, the protective effect occurring due to the presence of additives belonging to different classes of organic compounds namely, Phenol (aromatic alcohol), Acetone (aliphatic ketone), 4-Aminopyridine (aromatic heterocyclic nitrogen compound) and Hydrazine hydrate (aliphatic amine) on divalent iron ions during extended gamma irradiation, has been studied.

\section{Experimental}

\subsection{Chemicals}

1) A.R. Acetone, M.W. 58.08, Sp.gr. 0.7899, B.P. $56^{\circ} \mathrm{C}$, was obtained from British Drug Houses, UK. Phenol, M.W. 94.11, Sp.gr. 1.071, B.P. $181^{\circ}$ C, M.P. $41^{\circ} \mathrm{C}$; 4-Aminopyridine, M.W. 94.12, M.P. $158^{\circ} \mathrm{C}$ and Hydrazine hydrate, M.W. 50.06 Sp.gr. 1.03, B.P. $119^{\circ} \mathrm{C}$ were obtained from May \& Baker Co., UK. All these chemicals were used without further purification.

2) Extra pure Ferrous Ammonium Sulfate $\left(\mathrm{FeSO}_{4}\left(\mathrm{NH}_{4}\right)_{2} \mathrm{SO}_{4} \cdot 6 \mathrm{H}_{2} \mathrm{O}\right)$, Ferrous Sulfate $\left(\mathrm{FeSO}_{4} \cdot 7 \mathrm{H}_{2} \mathrm{O}\right)$ and Ferric Sulfate $\left(\mathrm{Fe}_{2}\left(\mathrm{SO}_{4}\right)_{3}\right)$ were obtained from May \& Baker Co., UK.

3) Analytical grade 1, 10-Phenanthroline (M.W. 180.21) was obtained from BDH, UK.

\subsection{Equipments}

Spectrophotometric measurement of samples were carried out using a double beam Shimadzu UV-VIS spectrophotometer type UV-210A. Glass or quartz cells were used whenever necessary.

\subsection{Preparation of Solutions}

All solutions were prepared using double distilled water over alkaline permanganate. The distilled water was boiled, then cooled and stored in glass stoppered flasks.

a) Preparation of iron solutions

Stock $10^{-2} \mathrm{M} \mathrm{Fe}(\mathrm{II})$ and $10^{-2} \mathrm{M}$ Fe(III) solutions were prepared as has been described before [6].

The concentration of Iron(II) ions in solutions was determined spectrophotometrically using $0.72 \%$ of 1,10 phenanthroline solution. The color was formed immediately after mixing at pH 2 - 3 and was indefinitely stable. 
The optical densities of the colored solutions were measured at $510 \mathrm{~nm}$ against a reagent blank prepared in the same way as the test solutions but without Fe(II) ions. For analysis of Fe(II) solutions a calibration curve was constructed within the concentration range $10^{-5}-1.5 \times 10^{-4} \mathrm{M}$ of $\mathrm{Fe}(\mathrm{II})$ ions. The molar absorptivity was equal to $1.16 \times 10^{4} \mathrm{dm}^{3} \cdot \mathrm{mol}^{-1} \cdot \mathrm{cm}^{-1}$.

The concentration of $\mathrm{Fe}(\mathrm{III})$ ions in solution was also determined spectrophotometrically at $305 \mathrm{~nm}$. A calibration curve for Fe(III) ions was constructed within the concentration range $5 \times 10^{-5}-5 \times 10^{-4} \mathrm{M}$ Fe(III). The molar absorbtivity of Fe(III) solutions was $2310 \mathrm{dm}^{3} \cdot \mathrm{mol}^{-1} \cdot \mathrm{cm}^{-1}$, which is in good agreement with the values cited in literature before [8].

b) Preparation of stock solutions of organic compound used as additives

Stock solutions were prepared by taking the appropriate amount of the organic compound and dissolving it in a certain volume of water.

Thus, a saturated phenol solution was prepared by dissolving $7.375 \mathrm{~g}$ of granular A.R. Phenol in the least amount of water with constant stirring for $30 \mathrm{~min}$. One $\mathrm{ml}$ of the resultant saturated solution was diluted to 100 $\mathrm{ml}$ and was used as a stock phenol solution. That solution was analyzed by adding $1.0 \mathrm{ml}$ to $100 \mathrm{ml}$ distilled water in a conical flask to which was added $40 \mathrm{ml}$ of $0.1 \mathrm{~N} \mathrm{KBrO} / \mathrm{KBr}$ solution and after adding $5 \mathrm{ml} \mathrm{conc}$. $\mathrm{HCl}$ the mixture was kept tightly closed in the conical flask for 15 minutes. Excess bromine was then determined by adding $10 \mathrm{ml}$ of $10 \% \mathrm{KI}$ solution and titrating the liberated $\mathrm{I}_{2}$ with standard $\mathrm{Na}_{2} \mathrm{~S}_{2} \mathrm{O}_{3}$ solution using starch indictor. The volume of reacted bromine solution was used to calculate the phenol concentration [9]. It has been found that the stock phenol solution contained $14.75 \mathrm{mg}$ phenol per $\mathrm{ml}$ i.e. $0.157 \mathrm{M}$.

In case of 4-aminopyridine a stock solution was prepared by dissolving $7.5296 \mathrm{~g}$ in $500 \mathrm{ml}$ water to give 0.16 M solution. Stock hydrazine hydrate solution was prepared by dissolving $1.9 \mathrm{ml}$ in water in a $250 \mathrm{ml}$ volumetric flask to give $0.16 \mathrm{M}$ solution. In case of acetone $5.9 \mathrm{ml}$ of acetone were transferred quantitatively and completed to the mark in a $500 \mathrm{ml}$ volumetric flask to give $0.16 \mathrm{M}$ solution.

\subsection{Preparation and Irradiation of Solutions}

Iron(II) solutions to be irradiated were prepared by taking $5 \mathrm{ml}$ of $10^{-2} \mathrm{M} \mathrm{Fe}(\mathrm{II})$ in $0.8 \mathrm{~N} \mathrm{H}_{2} \mathrm{SO}_{4}$ together with necessary amount of different organic additives and the mixtures were completed to the mark in 50 ml volumetric flasks with double distilled water. Fe(III) solutions to be irradiated were prepared in the same way as $\mathrm{Fe}(\mathrm{II})$ solutions but using $5 \mathrm{ml}$ of $10^{-2} \mathrm{M} \mathrm{Fe}(\mathrm{III})$. The resultant solutions were transferred to the glass irradiation tubes (15 cm long and $2.5 \mathrm{~cm}$ diameter). Each irradiation tube was provided with a neck $1 \mathrm{~cm}$ in diameter ending with a tight ground glass stopper. The tubes containing the solutions to be irradiated were introduced into a Canadian ${ }^{60} \mathrm{Co}$ gamma cell-220 for extended time intervals-up to about 60 days at absorbed dose rate of $0.43 \mathrm{kGy} /$ hour until $\mathrm{Fe}(\mathrm{II})$ ions were almost completely oxidized to $\mathrm{Fe}(\mathrm{III})$. At that point gamma exposure was terminated.

During the extended irradiation period of the iron solutions, 3 samples, $1 \mathrm{ml}$ each, were withdrawn daily from the irradiated solution and each diluted to $10 \mathrm{ml}$ and the concentration of existing Fe(II) was determined by measuring the absorbance. The percent remaining Iron(II) was calculated as follows:

$$
\% \text { existing (remaining) } \mathrm{Fe}(\mathrm{II}) \text { in irradiated samples }=\mathrm{A} / \AA \times 100
$$

where $\mathrm{A}$ is the $\mathrm{Fe}(\mathrm{II})$ concentration remaining after receiving a certain dose and $\AA$ is the initial $\mathrm{Fe}(\mathrm{II})$ concentration in the sample before irradiation. The calculated values were then plotted against the corresponding applied doses.

During irradiation special care was always taken to keep the position of the irradiation tubes unchanged during the whole irradiation period. In the presence of organic additives no adverse effects on the absorbance of $\mathrm{Fe}(\mathrm{II})$ or $\mathrm{Fe}(\mathrm{III})$ solutions were observed.

The dosimetry of the irradiation cell was occasionally checked by the well known Fricke dosimeter [3].

\subsection{Reaction Rate Constants}

In the present work, reaction rate constants $(k)$ in $\mathrm{dm}^{3} \cdot \mathrm{mol}^{-1} \cdot \mathrm{s}^{-1}$ were used as reported in the work of Anbar [10] [11]. For convenience the rate constant values are given without dimensions.

\section{Results and Discussions}

It is almost generally accepted, from the chemical point of view, that water radiolysis (by gamma radiations) 
leads to the formation of primary reactive species with the following $\mathrm{G}$ values [12].

$$
\begin{gathered}
\mathrm{H}_{2} \mathrm{O} \rightarrow \mathrm{e}_{a q}^{-}, \quad \mathrm{H} \cdot, \quad \mathrm{OH} \cdot \quad \mathrm{H}_{2}, \quad \mathrm{H}_{2} \mathrm{O}_{2}, \mathrm{H}^{+}, \quad \mathrm{OH}^{-} \\
\text {G values (2.7) (0.6) (2.8) (0.47) }(0.7)(0.32)(0.5)
\end{gathered}
$$

The hydrated electrons $\mathrm{e}_{a q}^{-}$, which are abundantly formed in water radiolysis, are readily converted to $\mathrm{H}$ atoms, particularly in acidic solutions [13]

$$
\mathrm{e}_{a q}^{-}+\mathrm{H}_{3} \mathrm{O}^{+} \rightarrow \mathrm{H} \cdot+\mathrm{H}_{2} \mathrm{O} \quad k=2.3 \times 10^{10}
$$

The standard reduction potential of $\mathrm{e}_{a q}^{-}$is $-2.9 \mathrm{~V}$. Consequently, it readily reduces inorganic ions having more positive reduction potentials [2], such as $\mathrm{Fe}^{3+}$, according to the following general equation:

$$
M_{a q}^{n+}+\mathrm{e}_{a q}^{-} \rightarrow M_{a q}^{(n-1)+}
$$

In case of $\mathrm{Fe}^{3+}$ the reaction rate constant is $3.5 \times 10^{8}$ at $25^{\circ} \mathrm{C}$ [14].

The hydrogen atom is the major reducing species in acidic solutions. Its standard reduction potential is $-2.3 \mathrm{~V}$ [15] [16] so it reduces most reducible substances but it is not as strong as $\mathbf{e}_{a q}^{-}$, with standard reduction potential $-2.9 \mathrm{~V}[2]$.

The hydroxyl radical $\mathrm{OH}$ is the principal oxidizing radical formed when aqueous solutions were subjected to gamma radiations [3]. It is a powerful oxidant having a standard reduction potential $2.7 \mathrm{~V}$ in acidic solution and $1.8 \mathrm{~V}$ in neutral solution [17] [18]. For example $\mathrm{OH}$ radicals readily oxidize inorganic ionic species such as $\mathrm{Fe}^{2+}$ in acidic solutions. Also it can add to unsaturated bonds [2].

In presence of oxygen (solubility of oxygen in water $0.25 \mathrm{mM} / \mathrm{L}$ ) another oxidizing species $\mathrm{HO}_{2}$, is formed in irradiated aqueous solutions according to the following reactions:

$$
\begin{gathered}
\mathrm{O}_{2}+\mathrm{e}_{a q}^{-} \rightarrow \mathrm{O}_{2}^{-} \cdot+\mathrm{H}_{2} \mathrm{O} \quad k=1.9 \times 10^{10} \\
\mathrm{O}_{2}^{-} \cdot+\mathrm{H}^{+} \rightarrow \mathrm{HO}_{2}
\end{gathered}
$$

$\mathrm{HO}_{2} \cdot$ could be also formed by the reaction,

$$
\mathrm{O}_{2}+\mathrm{H} \cdot \rightarrow \mathrm{HO}_{2} \quad k=2.1 \times 10^{10}
$$

$\mathrm{HO}_{2}$. radicals, which are normally formed in acidic solutions have a rather short half life and can act as oxidants but they are more weaker than the $\mathrm{OH} \cdot$ radicals [19].

The molecular products, $\mathrm{H}_{2}$ and $\mathrm{H}_{2} \mathrm{O}_{2}$, are formed by the combination of two $\mathrm{H} \cdot$ and two $\mathrm{OH} \cdot$ radicals to form $\mathrm{H}_{2}$ and $\mathrm{H}_{2} \mathrm{O}_{2}$ respectively. Molecular hydrogen is relatively inert and normally plays a little role in subsequent reactions in the gamma irradiated aqueous system. The small amount of $\mathrm{H}_{2} \mathrm{O}_{2}$ formed interacts with $\mathrm{H} \cdot$ and $\mathrm{OH}$. radicals to give $\mathrm{OH} \cdot$ and $\mathrm{HO}_{2}$. respectively together with water [3] [16]. $\mathrm{H}_{2} \mathrm{O}_{2}$ can serve as a mild oxidant and being present in traces its role could be ignored [20].

From the foregoing discussion it is clear that in gamma irradiated aqueous acidic solutions, $\mathrm{OH} \cdot$ and $\mathrm{H}$ - radicals could be considered as the main existing oxidizing or reducing species respectively. $\mathrm{HO}_{2} \cdot$ radicals can have a variable role depending on the concentration of oxygen present in the medium. Consequently, in the present work we shall concentrate on the effect of $\mathrm{OH} \cdot$ and $\mathrm{H} \cdot$ radicals being present as the main oxidizing or reducing species in the irradiated solutions.

In a previous publication, it has been reported that a $10^{-3} \mathrm{M}$ Fe(II) acidic solution $\left(0.08 \mathrm{~N} \mathrm{H}_{2} \mathrm{SO}_{4}\right)$ was completely oxidized when irradiated by gamma radiations for about 2 hours, at a gamma absorption dose rate of 310 gray/hour i.e. after absorbing about 620 grays [6].

Other authors reported that radiolytic oxidation of $\mathrm{Fe}^{2+}$ in gamma irradiated acidic solutions occurs mainly by the oxidizing species produced by water radiolysis namely $\mathrm{OH} \cdot$ radicals together with $\mathrm{HO}_{2}$. and $\mathrm{H}_{2} \mathrm{O}_{2}$ which can participate but to a rather limited extent [13].

The protective effect exerted by organic acids, aldehydes and alcohols on divalent iron ions during extended gamma irradiation has been reported before [7]. It was concluded that the protective effect is dependant on the type and concentration of the organic additive used.

In the present work, increasing amounts of phenol, acetone, 4-ethylpyridine and hydrazine hydrate were added to $10^{-3} \mathrm{M} \mathrm{Fe}(\mathrm{II})$ or $\mathrm{Fe}(\mathrm{III})$ acidic solutions $\left(0.08 \mathrm{~N} \mathrm{H}_{2} \mathrm{SO}_{4}\right)$ and the resultant solutions were subjected to 
extended gamma irradiation. Every day, samples were taken from the continuously irradiated solutions and the existing concentration of $\mathrm{Fe}(\mathrm{II})$ ions was determined spectrophotometrically. Knowing the initial concentration of $\mathrm{Fe}(\mathrm{II})$ before irradiation it was possible to determine \% Fe(II) remaining in irradiated solutions after exposure to increasing irradiation doses. These values were plotted against the corresponding irradiation doses in order to follow the change of $\mathrm{Fe}(\mathrm{II})$ in solution during continuous gamma irradiation.

\subsection{Valence Stabilization of Fe(II) Ions during Extended Gamma Irradiation in Presence of Phenol}

In a previous study, it has been shown that aliphatic alcohols can suppress Fe(II) oxidation due to the interaction between $\mathrm{OH}$ radicals and aliphatic alcohols leading to the formation of the corresponding aldehydes and acids [7].

It was interesting to study the capacity of an aromatic hydroxy compound e.g. phenol to be used as a protective agent against oxidation of $\mathrm{Fe}(\mathrm{II})$ ions in acidic solutions during continued gamma irradiation.

Figure 1 shows the change of $\mathrm{Fe}(\mathrm{II})$ concentration in acidic medium $\left(0.08 \mathrm{~N} \mathrm{H}_{2} \mathrm{SO}_{4}\right)$ during extended gamma irradiation in presence of different concentrations of phenol. The areas under the solid lines are taken to represent the actual protection occurring in each irradiated system.

The areas under the dashed lines are taken to represent $100 \%$ protection.

It is possible to observe that after absorbing about 10 - $11 \mathrm{kG}$ rays almost $75 \%$ of $\mathrm{Fe}(\mathrm{II})$ were transformed to the trivalent state. This could probably be due to the reaction of $\mathrm{OH} \cdot$ radicals, formed with a rather high $\mathrm{G}$ value (2.7), with Fe(II) ions initially present.

$$
\mathrm{Fe}^{2+}+\dot{\mathrm{H}} \rightarrow \mathrm{Fe}^{3+}+\mathrm{OH}^{-} \quad k=1.3 \times 10^{9}
$$

When the greater part of iron ions is in the trivalent state gradual reduction started to occur with continued irradiation. Reduction of $\mathrm{Fe}(\mathrm{III})$ occurs by the hydrogen radicals, at that stage present in greater amounts in the medium:

$$
\mathrm{Fe}^{3+}+\dot{\mathrm{H}} \rightarrow \mathrm{Fe}^{2+}+\mathrm{H}^{+} \quad k=8 \times 10^{7}
$$

From the data shown in Figure 1, it is clear that the speed of Fe(III) reduction during irradiation depends on the concentration of phenol used. The higher the concentration of phenol used, the more rapid will be the reduction process. This could be attributed to the fact that $\mathrm{OH} \cdot$ addition reactions to compounds containing Pi electrons, such as phenol occur at a higher rate constant as compared to the corresponding rate constant for the reaction of $\mathrm{OH} \cdot$ radicals with $\mathrm{Fe}(\mathrm{II})$ [13].
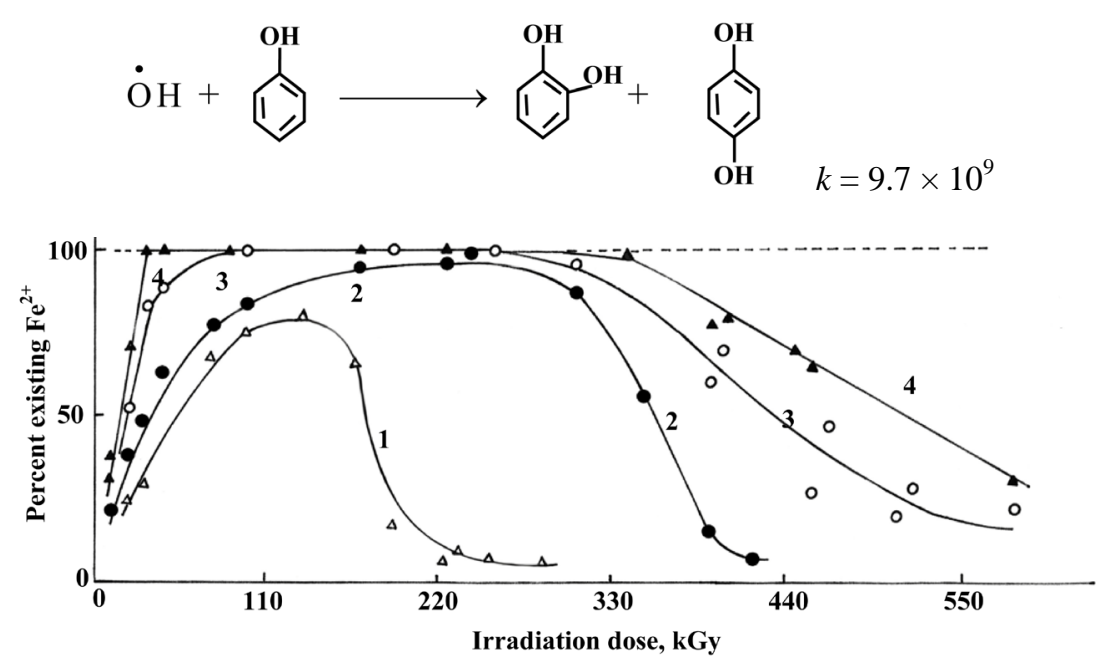

Figure 1. Percent existing $\mathrm{Fe}^{2+}$ in $\gamma$-irradiated $10^{-3} \mathrm{M} \mathrm{Fe}^{2+}$ solution $\left(0.08 \mathrm{~N} \mathrm{H}_{2} \mathrm{SO}_{4}\right)$ containing different concentrations of phenol: $1-0.32 \times 10^{-3} \mathrm{M} ; 2-0.96 \times 10^{-3} \mathrm{M} ; 3-1.6 \times 10^{-3} \mathrm{M} ; 4-3.2 \times 10^{-3} \mathrm{M}$. (-- - -) 100\% protection line; (—) Actual protection line. 
At that stage, while $\mathrm{OH} \cdot$ radicals are mainly engaged in the addition reaction to phenol, the hydrogen radicals accumulating in the medium continuously interact with $\mathrm{Fe}(\mathrm{III})$, thus leading to the gradual reduction of $\mathrm{Fe}(\mathrm{III})$ to $\mathrm{Fe}(\mathrm{II})$. Therefore, on using more phenol in the irradiated solution, $\mathrm{Fe}^{3+}$ reduction will occur more rapidly. Moreover, by analogy to the interaction of $\mathrm{H}$. radicals with benzene, the reaction of $\mathrm{H}$. radicals with phenol can also lead to the formation of the following adduct [13].

$$
\dot{\mathrm{H}}
$$

These addition products can further take part in the reduction of Fe(III) ions as follows

$$
\mathrm{Fe}^{2+}+
$$

After almost complete reduction of most of trivalent iron to the divalent state the protection of $\mathrm{Fe}(\mathrm{II})$ by existing phenol continues very probably as a result of the continued $\mathrm{OH}^{-}$addition reactions to phenol while the continuous formation of $\mathrm{H}$ and its further reaction to give $\mathrm{H}_{2}$

$$
\dot{\mathrm{H}}+\dot{\mathrm{H}} \rightarrow \mathrm{H}_{2}
$$

ensures the existence of reducing conditions in the medium. The protective effect of phenol continues until the end of the protection period, for durations dependant on the concentration of the added phenol. At the end of the protection period, $\mathrm{Fe}(\mathrm{II})$ is gradually oxidized until all iron is transformed to the trivalent state.

It should be pointed out that on using phenol, only one protection period occurred and not two as in case of aliphatic alcohols [7]. This may indicate that protection is due to the role of phenol molecule itself. It is also possible to observe that the protection capacity furnished by phenol is greater than that observed in case of aliphatic hydroxy compounds i.e. alcohols [7]. This could be attributed to the higher radiation stability of aromatic hydroxyl compounds due to the presence of the aromatic nucleus.

On using $\mathrm{Fe}(\mathrm{III})$ ions instead of $\mathrm{Fe}(\mathrm{II})$ ions the results obtained are shown in Figure 2. It could be observed that in presence of phenol gradual reduction of Fe(III) ions occurs and after their almost complete reduction the concentration of $\mathrm{Fe}$ (II) remained constant for rather long protection periods as compared to the case on using Fe(II) ions, shown in Figure 1. This could probably be attributed to the greater stability of phenol during extended gamma irradiation.

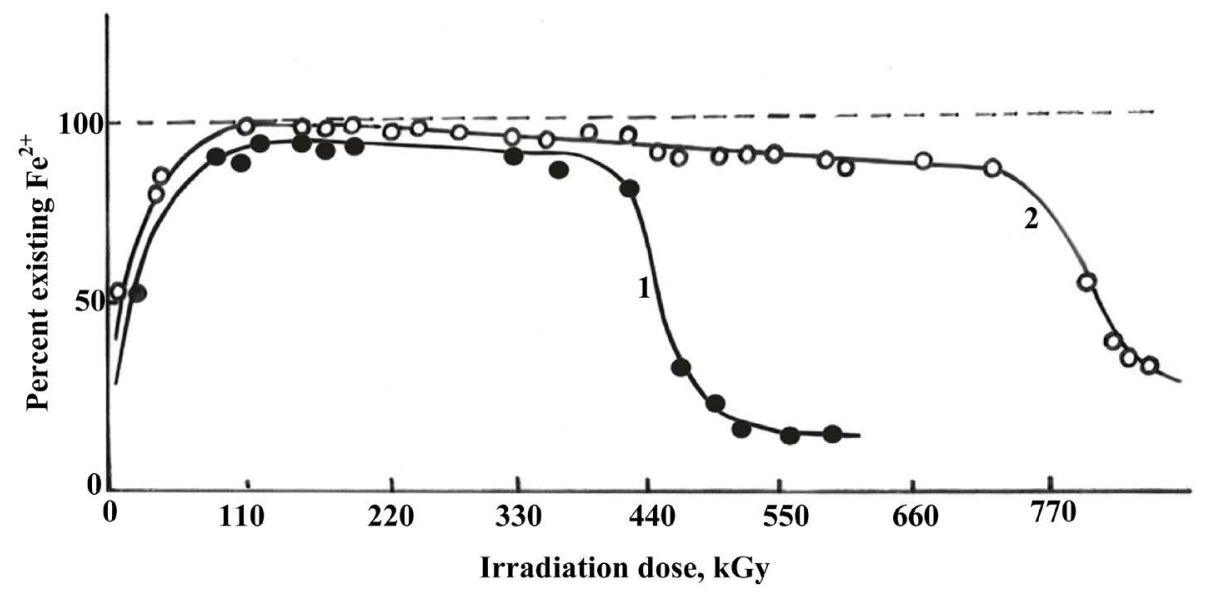

Figure 2. Percent existing $\mathrm{Fe}^{2+}$ in $\gamma$-irradiated $10^{-3} \mathrm{M} \mathrm{Fe}^{3+}$ solution $\left(0.08 \mathrm{~N} \mathrm{H}_{2} \mathrm{SO}_{4}\right)$ containing different concentrations of phenol: $1-0.96 \times 10^{-3} \mathrm{M} ; 2-1.6 \times 10^{-3} \mathrm{M}$. (-- - - -) $100 \%$ protection line; ( $\longrightarrow$ ) Actual protection line. 
At the end of irradiation traces of solid condensation products were found at the bottom of the irradiation tubes. This could be attributed to the formation of high molecular weight phenol condensation products after receiving rather high irradiation doses.

\subsection{Valence Stabilization of Fe(II) Ions during Extended Gamma Irradiation in Presence of Acetone.}

The solid lines shown in Figure 3 (the actual protection line) show the change of Fe(II) concentration during extended gamma irradiation of acidic Fe(II) solutions in presence of different concentrations of acetone.

It is clear that protection occurs in a single protection period. At first rapid oxidation of Fe(II) to Fe( III) occurs according to the following reaction.

$$
\mathrm{Fe}^{2+}+\dot{\mathrm{O}} \mathrm{H} \rightarrow \mathrm{Fe}^{3+}+\mathrm{OH}^{-} \quad k=1.3 \times 10^{9}
$$

. At the same time acetone is not effectively interfering due its relatively lower rate constant of reaction with $\dot{\mathrm{O} H}$ radicals

$$
\mathrm{CH}_{3} \mathrm{COCH}_{3}+\dot{\mathrm{O}} \mathrm{H} \rightarrow \dot{\mathrm{C}} \mathrm{H}_{2} \mathrm{COCH}_{3}+\mathrm{H}_{2} \mathrm{O} \quad k=1.1 \times 10^{8}
$$

When most of $\mathrm{Fe}(\mathrm{II})$ is changed to $\mathrm{Fe}(\mathrm{III})$, reduction of trivalent iron starts by $\mathrm{H}$ radical reactions and continues gradually according to the following reaction:

$$
\mathrm{Fe}^{3+}+\dot{\mathrm{H}} \rightarrow \mathrm{Fe}^{2+}+\mathrm{H}^{+} \quad k=1.3 \times 10^{7}
$$

At that stage acetone can only compete very slightly by the reaction

$$
\mathrm{C}_{3} \mathrm{COH}_{3}+\dot{\mathrm{H}} \rightarrow \mathrm{H}_{2}+\dot{\mathrm{C}} \mathrm{H}_{2} \mathrm{COCH}_{3} k=3.5 \times 10^{5}
$$

Reduction of Fe(III) continues until almost all iron ions were present in the divalent state whereby Fe(II) concentration remained almost constant until all acetone present was exhausted whereby oxidation of $\mathrm{Fe}(\mathrm{II})$ took place gradually until all iron ions were transformed to the trivalent state. Protection of Fe(II) occurred for periods of time dependant on the amount of added acetone.

This mechanism could be confirmed by observing the results obtained on irradiating Fe(III) instead of Fe(II) solutions. The results obtained are shown in Figure 4. A direct reduction step of Fe(III) occurred at first followed by valence stabilization of the formed Fe(II) which continued as long as acetone was still existing in the medium after which the concentration of Fe(II) ions gradually decayed being transformed to the trivalent state.

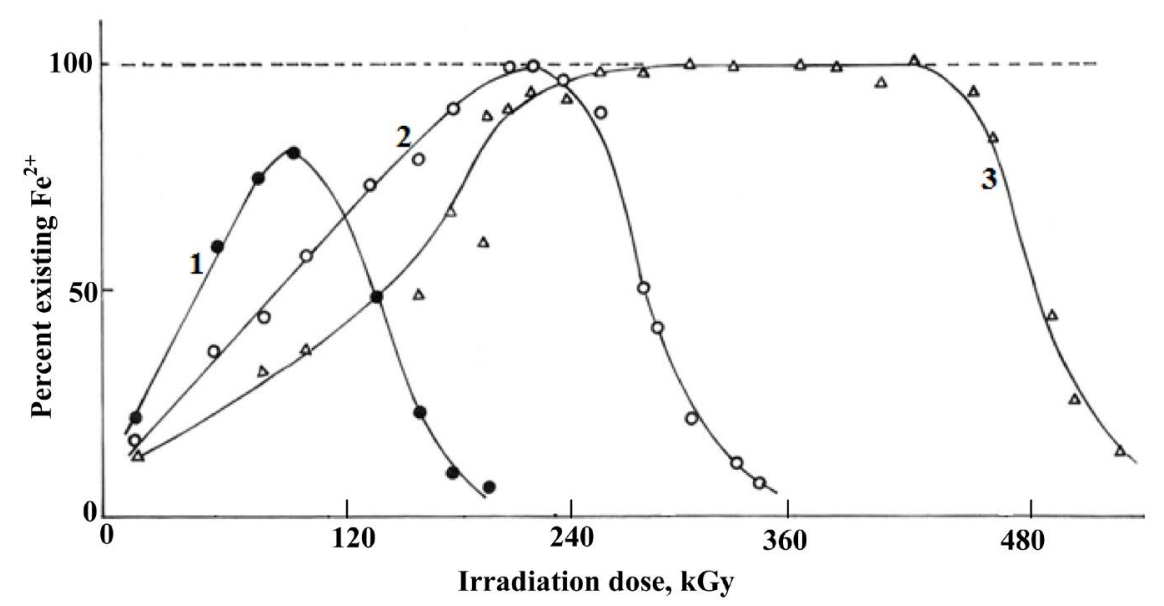

Figure 3. Percent existing $\mathrm{Fe}^{2+}$ in $\gamma$-irradiated $10^{-3} \mathrm{M} \mathrm{Fe}^{2+}$ solution $\left(0.08 \mathrm{~N} \mathrm{H}_{2} \mathrm{SO}_{4}\right)$ containing different concentrations of acetone: $1-3.2 \times 10^{-3} \mathrm{M} ; 2-8.0 \times 10^{-3} \mathrm{M} ; 3-16.0 \times 10^{-3} \mathrm{M}$. (-- - - $) 100 \%$ protection line; (—) Actual protection line. 


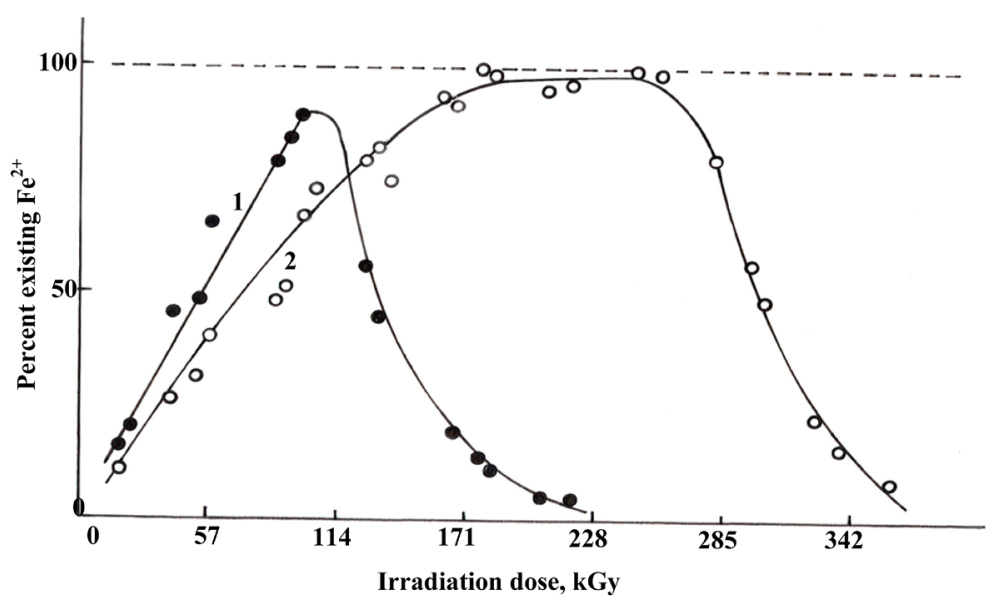

Figure 4. Percent existing $\mathrm{Fe}^{2+}$ in $\gamma$-irradiated $10^{-3} \mathrm{M} \mathrm{Fe}^{3+}$ solution $\left(0.08 \mathrm{~N} \mathrm{H}_{2} \mathrm{SO}_{4}\right)$ containing different concentrations of acetone: $1-3.2 \times 10^{-3} \mathrm{M} ; 2-8.0 \times 10^{-3} \mathrm{M}$; (----) $100 \%$ protection line; Actual protection line.

\subsection{Valence Stabilization of Fe(II) Ions during Extended Gamma Irradiation in Presence 4-Aminopyridine}

Figure 5 shows the change of the concentration of $\mathrm{Fe}(\mathrm{II})$ ions during extended gamma irradiation of acidic $\mathrm{Fe}(\mathrm{II})$ solutions in presence of different concentrations of 4-aminopyridine. The solid lines represent the actual protection lines of $\mathrm{Fe}(\mathrm{II})$ under these conditions and the dashed lines represent $100 \%$ protection.

It could be observed that at lower organic additive concentration, $\mathrm{Fe}(\mathrm{II})$ ions were first oxidized by $\mathrm{OH} \cdot$ radicals:

$$
\mathrm{Fe}^{2+}+\dot{\mathrm{O}} \mathrm{H} \rightarrow \mathrm{Fe}^{3+}+\mathrm{OH}^{-} \quad k=1.3 \times 10^{9}
$$

However, on increasing the organic additive concentration that reaction does not go to completion due to the interference of the organic additive and consequently a considerable part of iron ions is retained in the divalent state. At that stage reduction of any formed Fe(III) ions occurs gradually by hydrogen radicals either directly by the reaction,

$$
\mathrm{Fe}^{3+}+\dot{\mathrm{H}} \rightarrow \mathrm{Fe}^{2+}+\mathrm{H}^{+} \quad k=1.3 \times 10^{7}
$$

or indirectly through the formation of an adduct, by analogy to the case of phenol, as follows

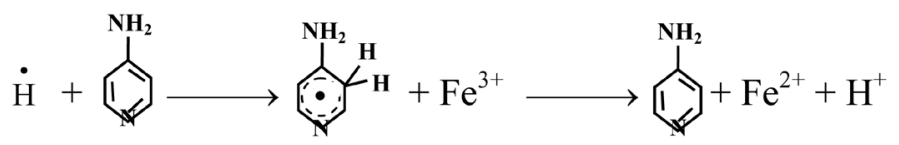

until almost complete reduction of the iron ions to the divalent state. At the same time $\mathrm{OH}$ radicals will be very probably interacting with the organic additive. After complete reduction of Fe(III), protection of the divalent state occurred by continued interaction of $\mathrm{OH} \cdot$ radicals with the organic additive: [21]
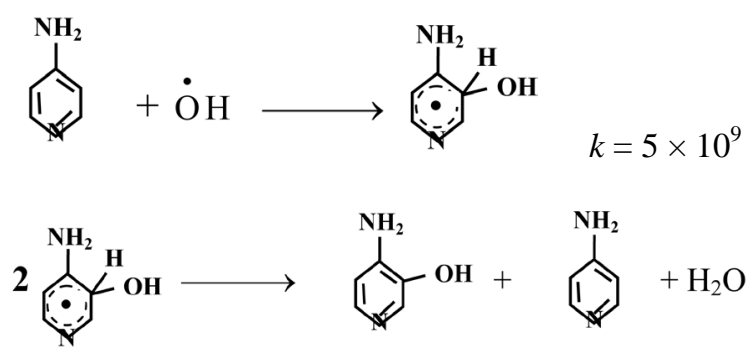


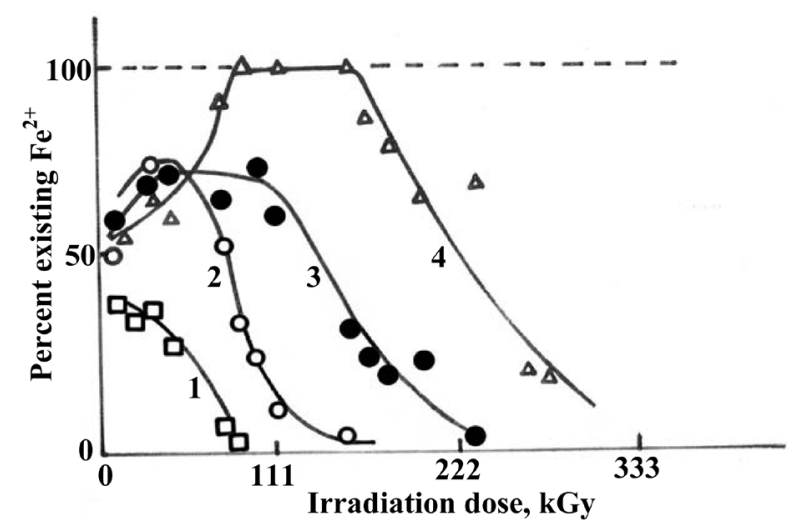

(a)

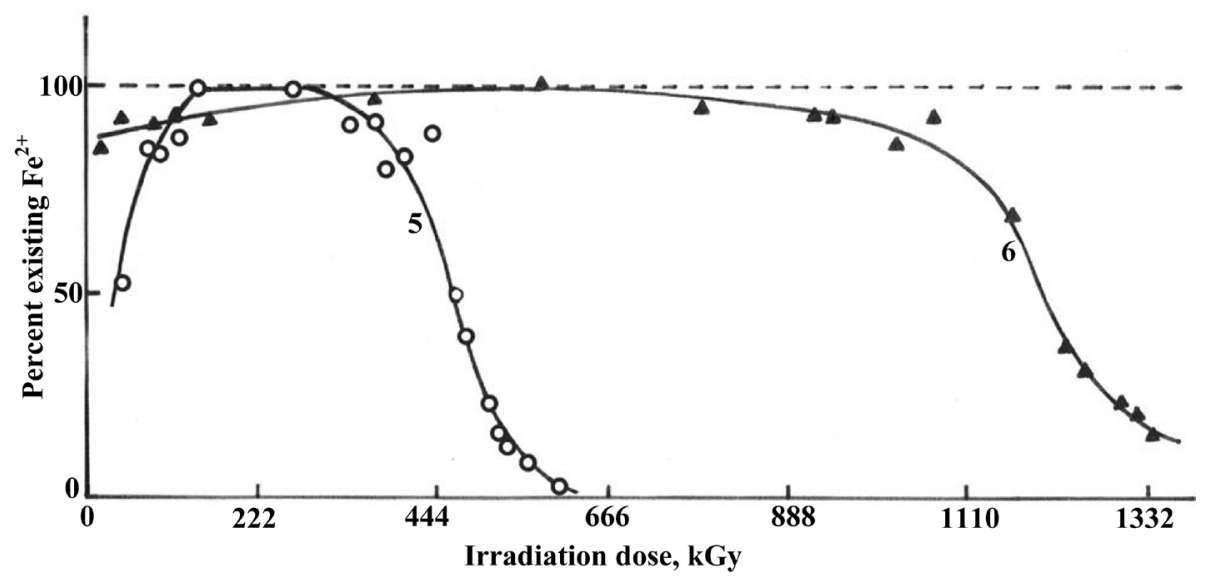

(b)

Figure 5. Percent existing $\mathrm{Fe}^{2+}$ in $\gamma$-irradiated $10^{-3} \mathrm{M} \mathrm{Fe}^{2+}$ solution $\left(0.08 \mathrm{~N} \mathrm{H}_{2} \mathrm{SO}_{4}\right)$ containing different concentrations of 4-amino pyridine: (a) $1-0.32 \times 10^{-3} \mathrm{M}$; $2-0.96 \times 10^{-3} \mathrm{M}$; 3-1.6 $\times 10^{-3} \mathrm{M}$; 4-3.2 $\times 10^{-3} \mathrm{M}$; (b) $5-8.0 \times 10^{-3}$ M; 6-16.0 $610^{-3}$ M. (-- - -) 100\% protection line; (- Actual protection line.

for periods dependant on the concentration of the additive used. When the latter is completely exhausted, Fe(II) is gradually oxidized to the trivalent state at the end of the protection period.

On using $\mathrm{Fe}(\mathrm{III})$ ions instead of $\mathrm{Fe}(\mathrm{II})$ in the irradiated solutions, the change of the percent existing $\mathrm{Fe}(\mathrm{II})$ is shown in Figure 6. It could be observed that $\mathrm{Fe}(\mathrm{III})$ is gradually reduced to $\mathrm{Fe}(\mathrm{II})$ and remained after that protected against oxidation during extended $\gamma$ irradiation until the organic additive was completely exhausted whereby oxidation of $\mathrm{Fe}(\mathrm{II})$ occurred gradually until the complete formation of the trivalent state.

\subsection{Valence Stabilization of Fe(II) Ions during Extended Gamma Irradiation in Presence of Hydrazine Hydrate}

It has been reported that upon gamma irradiation of $\mathrm{Fe}(\mathrm{II})$ ions in acidic solutions $\left(0.8 \mathrm{~N} \mathrm{H}_{2} \mathrm{SO}_{4}\right)$ in presence of hydrazine oxidation of $\mathrm{Fe}(\mathrm{II})$ is inhibited as a result of the competition between hydrazine-being a strong reducing agent-and $\mathrm{Fe}(\mathrm{II})$ ions for $\mathrm{OH}$ radicals [22]. The decrease in $\mathrm{Fe}^{3+}$ yield due to hydrazine is greatest at the highest dose rate. These results were explained quantitatively by assuming that hydrazine reacts with $\mathrm{OH}$ radicals to form hydrazyl radicals which either oxidize Fe(II) or combine to form ammonia. At a dose rate of $2 \times$ $10^{6} \mathrm{rad} / \mathrm{hr}$ about $90 \%$ of the hydrazyl radicals react to form ammonia [22].

$$
\begin{gathered}
\mathrm{Fe}^{2+}+\mathrm{OH} \rightarrow \mathrm{Fe}^{3+}+\mathrm{OH}^{-} \quad k=1.3 \times 10^{9} \\
\mathrm{NH}_{2} \mathrm{NH}_{2}+\dot{\mathrm{O}} \mathrm{H} \rightarrow \mathrm{H}_{2} \mathrm{O}+\mathrm{NH}_{2} \mathrm{NH} \quad k=1.4 \times 10^{10}
\end{gathered}
$$




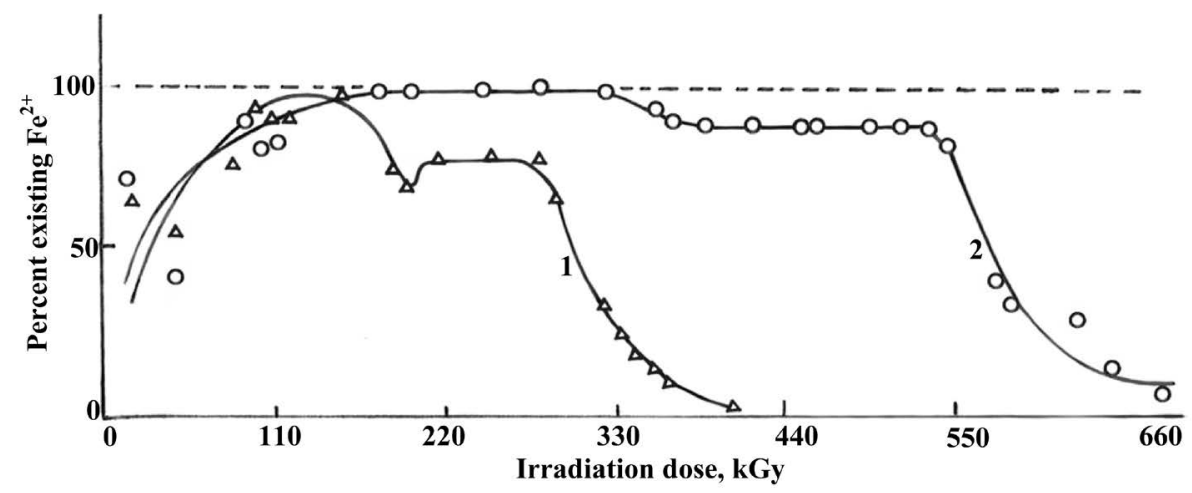

Figure 6. Percent existing $\mathrm{Fe}^{2+}$ in $\gamma$-irradiated $10^{-3} \mathrm{M} \mathrm{Fe}^{3+}$ solution $\left(0.08 \mathrm{~N} \mathrm{H}_{2} \mathrm{SO}_{4}\right)$ containing different concentrations of 4-amino pyridine: $1-3.2 \times 10^{-3} \mathrm{M}$; $2-8.0 \times 10^{-3} \mathrm{M}$. (-- - - -) $100 \%$ protection line; (-) Actual protection line.

$$
\begin{gathered}
\mathrm{NH}_{2} \mathrm{NH}^{\bullet}+\mathrm{NH}_{2} \mathrm{NH}^{\bullet} \rightarrow 2 \mathrm{NH}_{3}+\mathrm{N}_{2} \\
\mathrm{NH}_{2} \mathrm{NH}^{\bullet}+\mathrm{Fe}^{2+}+\mathrm{H}^{+} \rightarrow \mathrm{NH}_{2} \mathrm{NH}_{2}+\mathrm{Fe}^{3+}
\end{gathered}
$$

In the present work, the protective effect of hydrazine against the radiolytic oxidation of $\mathrm{Fe}(\mathrm{II})$ to $\mathrm{Fe}(\mathrm{III})$ has been investigated. Thus, $10^{-3} \mathrm{M} \mathrm{Fe}(\mathrm{II})$ solutions, $0.08 \mathrm{~N}$ in $\mathrm{H}_{2} \mathrm{SO}_{4}$ acid and containing increasing amount of hydrazine were irradiated in the $\gamma$-cell. The concentration of $\mathrm{Fe}(\mathrm{II})$ was followed during the extended irradiation period and the results obtained are shown in Figure 7. It could be observed that at the first phase of irradiation, oxidation of $\mathrm{Fe}(\mathrm{II})$ rapidly occurred and the greater the hydrazine concentration is used the lesser the extent of oxidation was observed, i.e. the greater is the protection of the Fe(II) ions. This could be understood by comparing the rate constants of $\mathrm{OH}$ radicals with $\mathrm{Fe}(\mathrm{II})$ and hydrazine.

On using $10^{-3} \mathrm{M} \mathrm{Fe}(\mathrm{II})$ solution containing increasing hydrazine concentrations, within the range $3.2 \times 10^{-3}$ $16 \times 10^{-3} \mathrm{M}$, protection gradually increased. It is clear from the data shown in Figure 7 that the protective effect of hydrazine is much more weaker than the effect observed in case of phenol, 4-aminopyridine, or other organic compounds studied before [7]. This could probably be attributed to the markedly lower radiation stability of hydrazine itself.

On using $\mathrm{Fe}(\mathrm{III})$ instead of $\mathrm{Fe}(\mathrm{II})$ ions, the general behavior was almost the same but the initial oxidation process observed in case of $\mathrm{Fe}(\mathrm{II})$ was replaced by an initial reduction stage until about $25 \%$ only of iron ions were present in the $\mathrm{Fe}(\mathrm{II})$ state. This is followed by a limited reduction step leading to a limited increase in the $\mathrm{Fe}(\mathrm{II})$ concentration. The formed Fe(II) remains weakly protected. This is followed by a gradual decay of $\mathrm{Fe}(\mathrm{II})$ leading to almost complete oxidation of Fe(II) after complete exhaustion of hydrazine.

Therefore, it could be concluded that although hydrazine is capable of inhibiting the oxidation of $\mathrm{Fe}$ (II) to $\mathrm{Fe}(\mathrm{III})$ in solution to a certain extent, it is a much more weaker protective agent for the lower valence state of iron ions. This might be also attributed to its rather lower radiation stability as compared to phenol or 4-aminopyridine.

\subsection{Relationship between the Concentration of the Organic Additives and the Resultant Valence Protection of Fe(II) during Extended $\gamma$ Irradiation}

By taking the areas under the actual protection lines in Figures 1-8 as a measure of the occurring protection in each case and plotting these values against the corresponding concentrations of the organic additives used it is possible to correlate the resultant protection with the amount of the organic additives used. The results are shown in Figure 9. Good linear relationships could be observed in case of acetone, 4-aminopyridine and hydrazine hydrate. On using Fe(III) ions instead of Fe(II) in the irradiated solution, protection of the formed Fe(II) was more pronounced than in case of using $\mathrm{Fe}(\mathrm{II})$ ions in solutions. This could probably be attributed to the fractional consumption of a part of the organic additive at the beginning of irradiation of $\mathrm{Fe}(\mathrm{II})$ while $\mathrm{Fe}(\mathrm{II})$ ions are being oxidized to Fe(III) ions.

On the other hand, in case of phenol it has been found that the protective effect of phenol is not dependant on 


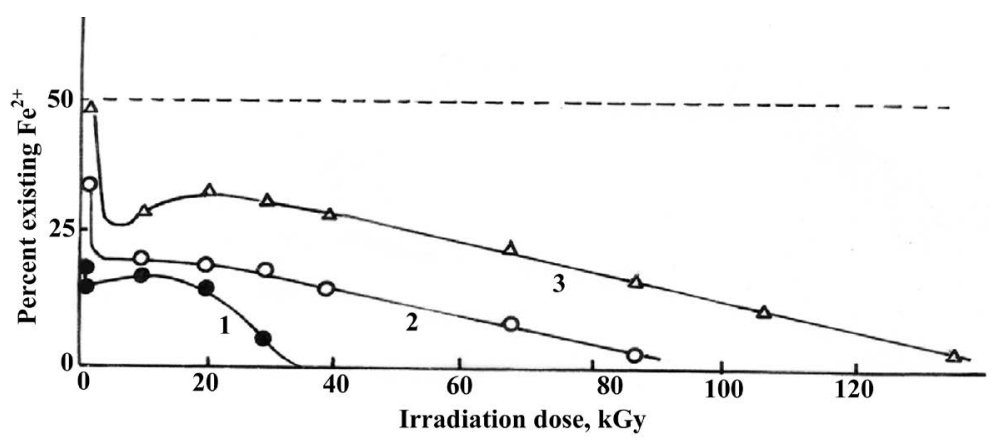

Figure 7. Percent existing $\mathrm{Fe}^{2+}$ in $\gamma$-irradiated $10^{-3} \mathrm{M} \mathrm{Fe}^{2+}$ solution $\left(0.08 \mathrm{~N} \mathrm{H}_{2} \mathrm{SO}_{4}\right)$ containing different concentrations of Hydrazine hydrate: $1-3.2 \times 10^{-3} \mathrm{M} ; 2-8.0 \times 10^{-3} \mathrm{M} ; 3-16.0 \times 10^{-3} \mathrm{M}$; ( $\longrightarrow$ Actual protection line; (-- - - - ) 50\% protection line.

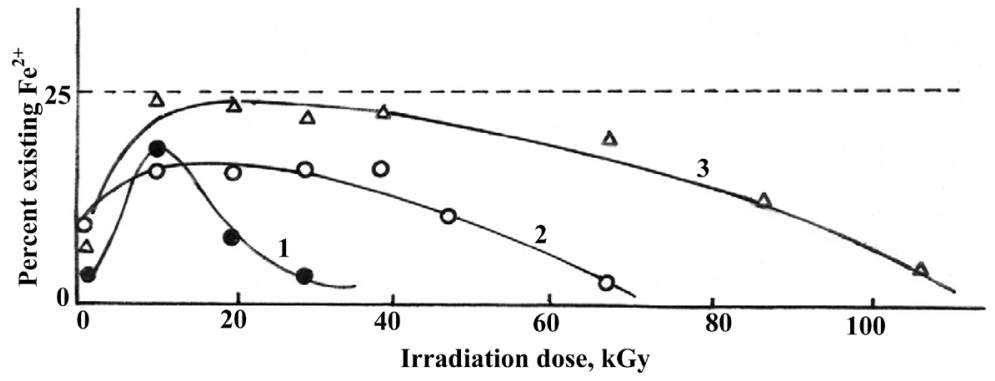

Figure 8. Percent existing $\mathrm{Fe}^{2+}$ in $\gamma$-irradiated $10^{-3} \mathrm{M} \mathrm{Fe}^{3+}$ solution $\left(0.08 \mathrm{~N} \mathrm{H}_{2} \mathrm{SO}_{4}\right)$ containing different concentrations of Hydrazine hydrate: $1-3.2 \times 10^{-3} \mathrm{M} ; 2-8.0 \times 10^{-3} \mathrm{M} ; 3-16.0 \times 10^{-3} \mathrm{M}$.

Actual protection line; (-----) $25 \%$ protection line.

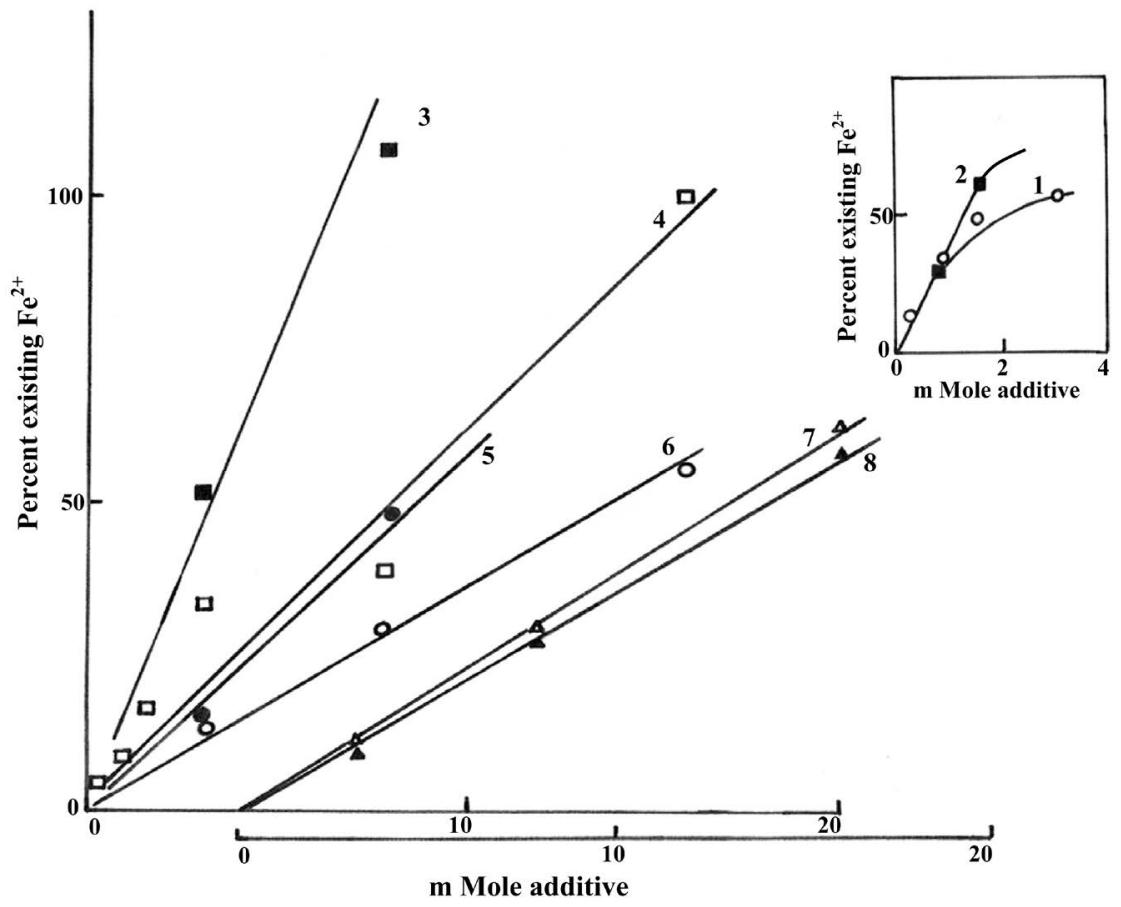

Figure 9. Relationships between the organic additive concentration and the area under the protection curve (in $\mathrm{cm}^{2}$ ): 1 -Phenol in presence of $\mathrm{Fe}^{2+} ; 5$ - Acetone in presence of $\mathrm{Fe}^{2+} ; 2$-Phenol in presence of $\mathrm{Fe}^{3+} ; 6$ - Acetone in presence of $\mathrm{Fe}^{3+} ; 3$-4-ethyl pyridine in presence of $\mathrm{Fe}^{3+} ; 7$-Hydrazine in presence of $\mathrm{Fe}^{2+} ; 4-4$-ethyl pyridine in presence of $\mathrm{Fe}^{2+} ; 7-$ Hydrazine in presence of $\mathrm{Fe}^{3+}$. 
phenol concentration above a certain concentration limit. In the square, shown in Figure 9, lines 1 and 2, the relationship between the total protection area and the concentration of the organic additive used, is shown. In both cases limited linearity could be observed, at concentrations much smaller than the other types of additives. This could probably be related to the formation of some solid condensation products observed at the bottom of the irradiation tubes after extended irradiation periods of the solutions.

In order to compare the protective capacity of different types of additives in different systems, the \% of total protection in each system was determined as follows:

$$
\% \text { total protection }=\left(A_{p} / A_{t}\right) \times 100
$$

where, $A_{p}$ is the area under the protection line and $A_{t}$ is the total area under the $100 \%$ protection line in all the Figures 1-8.

The percent of total protection is taken as a measure of the occurring protection due to the presence of a certain organic additive. The results obtained are given in Table 1 and are represented graphically in Figure 10, It

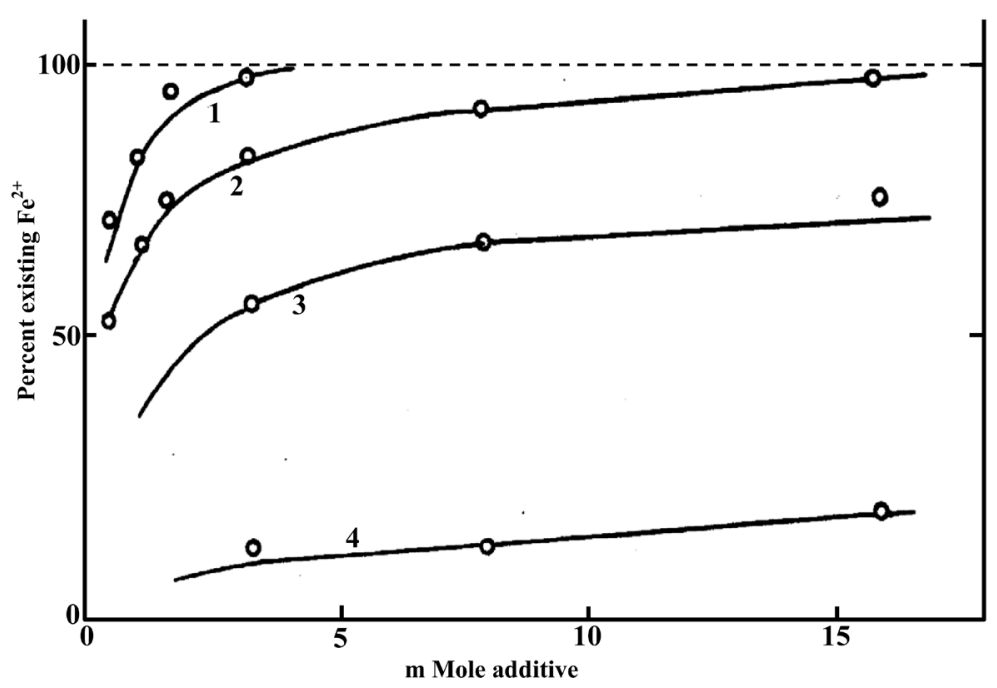

Figure 10. Change of \% total protection of gamma irradiated Fe(II) with the organic additive concentration used: 1—Phenol; 2-4-Aminopyridine; 3-Acetone; 4—Hydrazine hydrate.

Table 1. Percent protection of $1 \mathrm{mM}$ Fe(II) solution during extended of gamma irradiation in presence of different organic additive.

\begin{tabular}{|c|c|c|c|}
\hline Additive & Concentration used, mM & Total applied $^{\mathrm{a}}$ dose, $\mathrm{kGy}$ & Total protection ${ }^{\mathrm{b}} \%$ \\
\hline \multirow{3}{*}{ Hydrazine } & 3.2 & 34 & 12.5 \\
\hline & 8 & 98 & 12.4 \\
\hline & 16 & 145 & 18.3 \\
\hline \multirow{3}{*}{ Acetone } & 3.2 & 204 & 57 \\
\hline & 8 & 336 & 68 \\
\hline & 16 & 540 & 75 \\
\hline \multirow{6}{*}{ 4-Aminopyridine } & 0.32 & 84 & 54 \\
\hline & 0.96 & 120 & 68 \\
\hline & 1.6 & 207 & 76 \\
\hline & 3.2 & 296 & 24 \\
\hline & 8 & 547 & 92 \\
\hline & 16 & 1336 & 96 \\
\hline \multirow{4}{*}{ Phenol } & 0.32 & 191 & 72 \\
\hline & 0.96 & 405 & 84 \\
\hline & 1.6 & 585 & 97 \\
\hline & 3.2 & 700 & 98 \\
\hline
\end{tabular}

\footnotetext{
${ }^{\mathrm{a}}$ Total absorbed dose till complete decay of the used amount of additive; ${ }^{\mathrm{b}}$ Percent taken as a measure of the extent of actual overall protection.
} 
is possible to observe that the percent protection increases gradually on increasing the organic additive till a limiting value beyond which protection increases rather slowly on increasing the additive concentration. It is clear that phenol or 4 -aminopyridine gave the highest protection $\sim 90 \%$ or more, acetone gave about $60 \%$ protection while, on the other hand, hydrazine gave poor protection during irradiation.

On using $\mathrm{Fe}(\mathrm{III})$ in the irradiated solutions instead of $\mathrm{Fe}(\mathrm{II})$ a similar general behavior was observed.

\subsection{Combating against Crud Formation in Nuclear Boiling Water Reactors}

Ishigure [5] reported that gamma radiations enhance the release of iron crud from stainless steel and carbon steel in nuclear power reactors, particularly in BWR. The crud $\left(\alpha-\mathrm{F}_{2} \mathrm{O}_{3}\right)$ formation mechanism was assumed to occur as follow:

$$
\begin{gathered}
\mathrm{Fe}+1 / 2 \mathrm{O}_{2}+2 \mathrm{H}^{+} \rightarrow \mathrm{Fe}^{2+}+\mathrm{H}_{2} \mathrm{O} \\
2 \mathrm{Fe}^{2+}+1 / 2 \mathrm{O}_{2}+2 \mathrm{H}^{+} \rightarrow 2 \mathrm{Fe}^{3+}+\mathrm{H}_{2} \mathrm{O} \\
\mathrm{Fe}^{2+}+\mathrm{OH} \rightarrow \mathrm{Fe}^{3+}+\mathrm{OH}^{-} \\
\mathrm{Fe}^{3+}+3 \mathrm{H}_{2} \mathrm{O} \rightarrow \mathrm{Fe}(\mathrm{OH})_{3}+3 \mathrm{H}^{+} \\
2 \mathrm{Fe}(\mathrm{OH})_{3} \rightarrow \mathrm{Fe}_{2} \mathrm{O}_{3}+3 \mathrm{H}_{2} \mathrm{O}
\end{gathered}
$$

These authors assumed that the oxidation reaction of ferrous ions is the rate determining reaction. Based on our present and previous studies on valance stabilization of $\mathrm{Fe}$ (II) upon extended gamma irradiation [6] [7] it could be assumed that if the Fe(II) oxidation reaction, in the suggested crud formation mechanism is suppressed or even stopped by adding certain amounts of organic additives as for example alcohols, phenol or organic acids, crud formation could be reduced and thus several problems usually caused by crud formation in boiling water reactor internals could be solved. This requires more work along that line to identify various parameters to be addressed in that respect.

\section{Conclusions}

1) $\mathrm{Fe}(\mathrm{II})$ ions in acidic solutions can be effectively protected during extended gamma irradiation in presence of phenol,4-aminopyridine and partly in presence of acetone.

2) Hydrazine which is normally an effective reducing agent offers poor protection to $\mathrm{Fe}(\mathrm{II})$ ions upon extended gamma irradiation.

3) The extent of protection depends on the type and amount of the additive used.

4) Organic additives to cooling water in boiling water reactors can play an effective role in combating against crud formation.

\section{References}

[1] Minder, W. (1953) Comparative Study of Protective Effects in Irradiation of Specific Systems. Strahlentherapie, 91, 126-134.

[2] Buxton, G.V., Greenstock, C.L., Philip Helman, W. and Ross, A. (1988) Critical the Rate Constants for Reactions of Hydrated Electrons, Hydrogen Atoms and Hydroxyl Radicals in Aqueous Solutions. The Journal of Physical Chemistry, 17, 513.

[3] Spinks, J.W.T. and Woods, K.J. (1990). Introduction of Radiation Chemistry. 3rd Edition, John Wiley \& Sons, New York, 259, 277, 283, 350, 352.

[4] Burton, M. and Lipsky, S. (1957) Mechanisms of Protection in Radiolysis of Organic Systems. The Journal of Physical Chemistry, 61, 1461-1465. http://dx.doi.org/10.1021/j150557a003

[5] Ishigure, K. (1983) Radiation Chemistry Related to Nuclear Power Technology. Radiation Physics and Chemistry, 22, 119-129. http://dx.doi.org/10.1016/0146-5724(83)90198-X

[6] Barakat, M.F. and Abdelhamid, M.M. (1996) Valence Stabilization of Polyvalent Ions during Gamma Irradiation of Aqueous Solutions by Sacrificial Protection. I-Valence Stabilization of Fe(II) Ions by Sulfite Ions. Journal of Radioanalytical and Nuclear Chemistry, 207, 171-182. http://dx.doi.org/10.1007/BF02036537

[7] Barakat, M.F. and Abdelhamid, M.M. (2013) Valence Stabilization of Polyvalent Ions during Gamma Irradiation of 
Aqueous Solutions by Sacrificial Protection. (III) Valence Stabilization of Fe(II) Ions by Organic Additives. Journal of Radioanalytical and Nuclear Chemistry, 298, 1619-1627. http://dx.doi.org/10.1007/s10967-013-2610-z

[8] Holn, W.B. (1970) Manual of Radiation Dosimetry. Academic Press Inc., New York, 313.

[9] Welcher, F.J. (1963). Standard Methods of Chemical Analysis. 6th Edition, Van Nostrand Reinhold Company, New York, V.2 Part B, 2464.

[10] Anbar, M. and Neta, P. (1963) Tables of Bimolecular Rate Constants of Hydrated Electrons, Hydrogen Atoms and Hydroxyl Radicals with Inorganic and Organic Compounds. The International Journal of Applied Radiation and Isotopes, 16, 227-242. http://dx.doi.org/10.1016/0020-708X(65)90176-6

[11] Anbar, M. and Neta, P. (1967) A Compilation of Specific Bimolecular Rate Constants for the Reactions of Hydratd Electrons, Hydrogen Atoms and Hydroxyl Radicals with Inorganic and Organic Compounds in Aqueous Solutions. The International Journal of Applied Radiation and Isotopes, 18, 493-523. http://dx.doi.org/10.1016/0020-708X(67)90115-9

[12] Getoff, N. (1996) Radiation-Induced Degradation of Water Pollutants—State of the Art. Radiation Physics and Chemistry, 47, 581-593. http://dx.doi.org/10.1016/0969-806X(95)00059-7

[13] Donnel, J.H.O. and Sangster, D.F. (1970) Principles of Radiation Chemistry. Edward Arnold Publishers Ltd., London, 85, 92, 95, 88.

[14] Sullivan, J.C., Gordon, S., Cohen, D., Mulac, W. and Schmidt, K.H. (1976) Pulse Radiolysis Studies of U(VI), Np(V), $\mathrm{Np}(\mathrm{VI})$ and $\mathrm{Pu}(\mathrm{VI})$ in Aqueous Perchlorate Media. The Journal of Physical Chemistry, 80, 1684.

[15] Swallow, A.J. (1973) Radiation Chemistry: An Introduction. Wiley, New York.

[16] Schwarz, H.A. (1981) Free Radicals Generated by Radiolysis of Aqueous Solutions. Journal of Chemical Education, 58, 101-105. http://dx.doi.org/10.1021/ed058p101

[17] Koppenol, W.H. and Liebman, J.F. (1984) The Oxidizing Nature of the Hydroxyl Radical. A Comparison with the Ferryl Ion $\left(\mathrm{FeO}_{2}^{+}\right)$. The Journal of Physical Chemistry, 88, 99-101. http://dx.doi.org/10.1021/j150645a024

[18] Klanning, U.K., Sehested, K. and Holman, J. (1985) Standard Gibbs Energy of Formation of the Hydroxyl Radical in Aqueous Solutions. Rate Constants for the Reaction $\mathrm{ClO}_{2}^{-}+\mathrm{O}_{3} \leftrightarrow \mathrm{O}_{3}^{-}+\mathrm{ClO}_{2}$. The Journal of Physical Chemistry, 89, 760-763. http://dx.doi.org/10.1021/j100251a008

[19] Scholes, G. and Weiss, J. (1959) Oxygen Effects and Formation of Peroxides in Aqueous Solutions. Radiation Research Supplement, 1, 177-189. http://dx.doi.org/10.2307/3583638

[20] Panchenkov, G.M. and Lebedev, V.P. (1979) Chemical Kinetics and Catalysis. Mir Publishers, Moscow, 362.

[21] Shevchuk, L.G., Zhikharev, V.S. and Vysotskaya, N.A. (1969) Kinetics of Reactions of Hydroxyl Radicals with Benzene and Pyridine Derivatives. Zhurnal organ. KHimii, 5, 1606.

[22] Ahrens, R.W. (1962) Gamma Irradiation of Aqueous Solutions of Fe(II)-Hydrazine. The Journal of Physical Chemistry, 66, 2108-2111. http://dx.doi.org/10.1021/j100817a007 